\title{
BMJ Open Exploring determinants of health provider choice and heterogeneity in preference among outpatients in Beijing: a labelled discrete choice experiment
}

Jingrong Zhu, Jinlin Li, Zengbo Zhang, Hao Li, Lingfei Cai

To cite: Zhu J, Li J, Zhang Z, et al. Exploring determinants of health provider choice and heterogeneity in preference among outpatients in Beijing: a labelled discrete choice experiment. BMJ Open 2019;9:e023363. doi:10.1136/ bmjopen-2018-023363

- Prepublication history for this paper is available online. To view these files, please visit the journal (http://dx.doi.org/10 1136/bmjopen-2018-023363).

Received 3 April 2018 Revised 19 November 2018 Accepted 4 March 2019

\section{Check for updates}

(C) Author(s) (or their employer(s)) 2019. Re-use permitted under CC BY-NC. No commercial re-use. See rights and permissions. Published by BMJ.

School of Management and Economics, Beijing Institute of Technology, Beijing, China

Correspondence to

Professor Jinlin Li:

1013899896@qq.com

\section{ABSTRACT}

Objective For a long time in China, public hospitals have been the most prominent provider of healthcare. However, recent policy reforms mean the private sector is experiencing rapid development. Thus, the purpose of this study is to detect whether the policies published by the government aimed to improve the quality of healthcare services were catering to patient's preferences.

Participants and methods Our work uses dental care as an example of services provided in outpatient setting and takes advantage of a labelled discrete choice experiment with a random sample of respondents from Beijing. Participants were asked to make a choice between four healthcare providers with different attributes. Mixed logit and latent class models were used for the analysis.

Result Care provided by high-level private hospitals and community hospitals were valued RMB154 and 216 less, respectively, than care provided by class A tertiary hospitals, while the most disliked provider was private clinics. This was the most valued attribute of dental care. Respondents also value: lower waiting times, the option to choose their doctor, lower treatment costs, shorter travel times and a clean waiting room. However, when the level of provider was analysed, the prevailing notion that patients in China were always likely to choose public services than private services no longer holds. Four classes of patients with distinct preferences for dental care provider choice were identified, which can partly be explained by age, income, experience and Hukou status-a household registration permit.

Discussion The study to some extent challenged the overwhelming predominance of public healthcare providers in China. The preference heterogeneity we found was relatively large. Our findings are significant for providers in developing more specific services for patients and for policymakers in weighing the pros and cons of future initiatives in medical reform.

\section{INTRODUCTION}

In China, public hospitals are graded according to the level and type of healthcare services they provide. Class A tertiary hospitals sit at the city, provincial or national level
Strengths and limitations of this study

- The level of private health provider was first considered in our study, and to our knowledge, this is the first article to explore patient preference for traditional low-level versus modern high-level private healthcare sectors.

- For the first time, Hukou status is divided into non-Beijing Hukou holders and Beijing Hukou holders rather than traditional rural-urban Hukou status division to explore the importance of cross-regional medical treatment policy in China.

- By using a labelled discrete choice experiment, the experiment design could provide each type of provider with specific attribute's levels, so that they are fair to reflect the healthcare reality in China.

- This survey will be undertaken in Beijing, China which could affect generalizability to other settings.

and are equipped with specialised medical resources and highly specialised medical experts. Community hospitals provide primary care at the rural or community level. They typically have limited resources and specialists; thus, they can only handle straightforward cases that do not require elaborate or sophisticated diagnostic and therapeutic facilities. The case in China now is that the dental department in tertiary public hospitals continue to swarm with patients, as community hospitals usually provide patient's with low quality of treatment and some community hospitals even cannot handle the highly technical filling cavity procedure. For a long time, private health sectors suffered from varieties of challenges including low patient recognition, lack of qualified physicians, low Bureau of Medical Insurance coverage and weaker support from local authorities in issues such as land use, taxation and government subsidies, which lead to the long-term dominant 
position of public health sectors in China's healthcare system. ${ }^{1}$ That was the case for a simple dental care procedure dental care. However, recent initiatives to reform China's medical system are changing the landscape of healthcare choices. Since 2013, public authorities in China have been launching a series of reforms and packages aimed at removing red tape surrounding investments in healthcare and enabling private capital inflows into the healthcare industry. The private healthcare providers began to witness a rapid expansion. As a result, by the end of 2017, the number of private hospitals had reached 18000 , accounted for $60 \%$ of all hospitals, up from just 17\% in 2005 according to the National Health and Family Planning Commission. ${ }^{2}$ Despite the rapid growth in the number of the private institutions, most of these private hospitals (with fewer than 100 beds) started off as clinics and faced significant obstacles to hire experienced clinicians. However, Chinese patients tend to prefer seeking medical attention from tertiary or teaching institutions, often searching out the most famous doctors to take on their cases. Yet, the remaining $40 \%$ of public hospitals still treated over $86 \%$ of medical cases. ${ }^{3}$ Tertiary public hospitals continue to swarm with patients. This places a heavy revenue burden on the government and has resulted in an inevitable deterioration in the quality, efficiency and even the accessibility of tertiary hospitals. ${ }^{4}$ As a partial consequence, and because the Chinese population is growing older and wealthier, a great gap has emerged between supply and demand..$^{5}$

To alleviate this gap and to improve the efficiency of medical services, the government introduced a series of policy reforms. ${ }^{6}$ For instance, medical alliances have been established that aligns one tertiary hospital with several secondary hospitals and community health institutions to cater to different medical demands within a hierarchical medical system, which helps to make more reasonable use of medical resources and improves services in less developed areas. Moreover, the new wave of excitement surrounding China's private medical service development comes from the set of policies announced by the government in 2016 aimed at removing resourcing barriers by enlarging the scale of the private hospitals and relaxing the requirement for physicians to practice at single sites. ${ }^{1}$ Traditionally, private clinics provided patients with poor quality healthcare. However, as the remaining challenges start to dissipate, successful private providers begin to transform themselves into high-level healthcare providers featured with reasonably up-to-date medical technology and skilled staff in large cities, such as Beijing and Shanghai, and begin to earn the trust of a broader spectrum of Chinese society. They are highly expensive and typically cater to the needs of a smaller pool of medical tourists, more affluent local citizens and those who seek patient-centric care.

However, these policy reforms also raise questions. Is the development of modern high-level private providers oriented towards the market in China? Should private hospitals join with public hospitals and operate as a part of a medical alliance? In addition, there have been recent reports that future policy reforms will require tertiary public hospitals to close their outpatient departments. These reports evoked much controversy nationwide. So, while all the policy reforms appear to be beneficial for improving the allocation of medical resources, whether they cater to patients' preferences remains a matter for debate.

Patient-centred care is an eternal topic in high-quality healthcare. ${ }^{7}$ Thus, it is critical for healthcare workers to determine their patients' preferences for healthcare services. Discrete choice experiment (DCE) can be used to generate realistic options for a particular context and independently test the factors that patients value in their decision making. ${ }^{89}$ Compared with other methods that use questionnaires to explore the determinants of provider choice in outpatient care, a DCE provides a quantitative examination of the influence each of those factors has on a patient's decision.

Although DCEs have already been widely used to understand the value patients place on a variety of healthcare demands, to the best of our knowledge, only a few studies using the DCE method have focused on patient preferences for health providers. ${ }^{10-12}$ Brown and his colleagues found the most important determinant in hospital choice in New Zealand was sector: public or private. ${ }^{10}$ In China, the distribution of providers in the healthcare market is uneven. ${ }^{13}$ Tang and his colleagues divided public hospitals into A-level public and C-level public hospitals and also found that respondents were far more likely to choose a public hospital than a private hospital. ${ }^{11}$ Yet, ignoring the gap between private healthcare providers may not be appropriate for current China's conditions. As the barriers of the development of private healthcare providers start to dissipate, the gap between private providers is becoming more and more considerable, both in quality and in service. However, the impacts of private providers' level on patients are still unknown in current literature. Thus, in this paper, we made contribution to subdivide private care sectors into high-level private and small private providers as the same way public healthcare sectors are usually divided to explore whether the level of provider is a significant determinant in an outpatient's choice of provider. Specially, our study will make clear of patients' recognition and preference for traditional low-level versus modern high-level private healthcare sectors.

Patients often have diverse expectations about, and preferences for, healthcare interventions. ${ }^{14}$ Furthermore, studies have shown that ignoring preference heterogeneity may bias the utility estimates derived from DCE studies. ${ }^{15} 16$ However, there is limited information about preference heterogeneity in the delivery of outpatient care. Through this study, we also aim to provide insights into the underlying structure of heterogeneity, thereby supporting greater penalisation of outpatient services. As one of China's oldest tools for population control, Hukou is essentially a household registration permit-akin to an 
internal passport—and plays a vital role in one's eligibility for local public services and programmes. ${ }^{17} 18$ Considering the diversity of China's migrant population, Hukou status was divided into two categories: temporary migrants without household registration in Beijing (non-Beijing Hukou holders) and native residents (Beijing Hukou holders) and incorporated into the heterogeneity calculations.

Additionally, labels have been widely used in marketing research and have already been used to examine the field of healthcare. ${ }^{19}$ As such, we explicitly chose a labelled DCE design so as to investigate the intangible and difficult-to-measure factors that influence the provider type patients choose and the strength of their preference. Thus, our research uses a labelled DCE to understand the general public's healthcare-seeking behaviour, specially the heterogeneity in patients' demands and their preferences for outpatient care in China. A central theme of recent healthcare reforms has been a redefinition of the roles of the public and private providers. Our study made contributions in institutional economics by focusing on the evolutionary process of health provider, understanding the role of the complex interaction of these various institutions in shaping economic behaviour and medical care market, which could help governments to arrive at more rational decisions on these reforms. Meanwhile, this information will be indispensable for formulating appropriate solutions for the questions and debated issues arising from China's current medical reforms and enacting the right policies for policy makers to improve outpatient satisfaction.

\section{METHODS}

DCE is a popular evaluation method that forces respondents, when making a choice, to consider a trade-off between attributes that are known to be valued within a hypothetical market where not all preferences can be satisfied. ${ }^{80-24}$ Where real data are not available, the data collected through DCEs is used to model the relative importance of various realistic choices in healthcare options. The results of some of these studies have provided valuable information to policymakers with limited healthcare budgets.

Our hypothetical scenario involves a patient with a cavity seeking dental care. We chose this scenario for several reasons: first, dental care is a common and prevalent outpatient need and is usually provided as a non-urgent service. Second, most people should be able to afford the cost of filling a cavity. Third, dental care is a well-developed outpatient service for private hospitals in China, which creates an appropriate context for our study.

\section{Attribute and level selection}

The attributes and their corresponding levels included in the study were developed using qualitative methods. An initial set of attributes was derived from a literature review and subsequently refined through interviews with potential dental patients and specialists and through a pilot test. ${ }^{25}$ The literature review of previous research revealed a number of attributes identified as important factors. Four outpatient doctors working in the public and private healthcare sectors were then invited to evaluate the attributes and recommend any changes to the list. To confirm the attributes of most importance to outpatients, 31 people were recruited to participate in semistructured interviews. The participants were asked to describe the most important attributes when seeking outpatient healthcare services and rank those attributes according to the list developed from the literature review. During the interviews, more than half the participants stated that the level of both public and private provider might have a significant influence on their decision. This is consistent with our prior claim that simply classifying providers as public and private may not be appropriate for the Chinese context. The four physicians also reviewed the results of the interviews, along with two health systems researchers, to determine the final attributes and attribute levels and to refine the wording used in the questionnaire.

Based on the process described above, six attributes were defined for the pilot study. The pilot test was conducted with 23 patients on a waiting list for dental treatment. The type of hospital was divided into four levels: class A tertiary hospitals, community hospitals, high-level private hospitals and small private clinics. The levels for the remaining five attributes were set to be consistent with previous studies. ${ }^{26-29}$ The levels for waiting environment, option to choose doctor and travel times were set specifically to ensure the plausibility of the scenario. Waiting time initially had generic levels across tertiary hospitals, community hospitals, private hospitals and clinics. However, due to doubts expressed by many participants over waiting for more than half an hour in a private provider before treatment, waiting time for private facilities was limited to less than half an hour. The minimum and maximum out-of-pocket costs were determined by the expert group and the patients; the levels were set as a division of this range. The results of the pilot test, combined with information described above, were used to conform the appropriateness of the levels for each attribute and to improve the clarity of the survey for respondents. Table 1 lists the final set of attributes and their levels.

\section{Experiment design}

The experiment design contained four constraints: (1) the travel time to community hospitals was limited to $20 \mathrm{~min}$; (2) waiting times for private facilities were restricted to less than half an hour; (3) the waiting environment for high-level hospitals were limited to only quiet, clean and tidy; and (4) the choice of doctor attribute was only offered for class A tertiary hospitals for consistency with real-world options. A D-efficient fractional factorial design was created to minimise standard errors and covariances of the parameter estimates. ${ }^{30-32}$ The attribute levels for waiting environment, waiting time, choice of 
Table 1 Attributes and levels used in the labelled discrete choice experiment

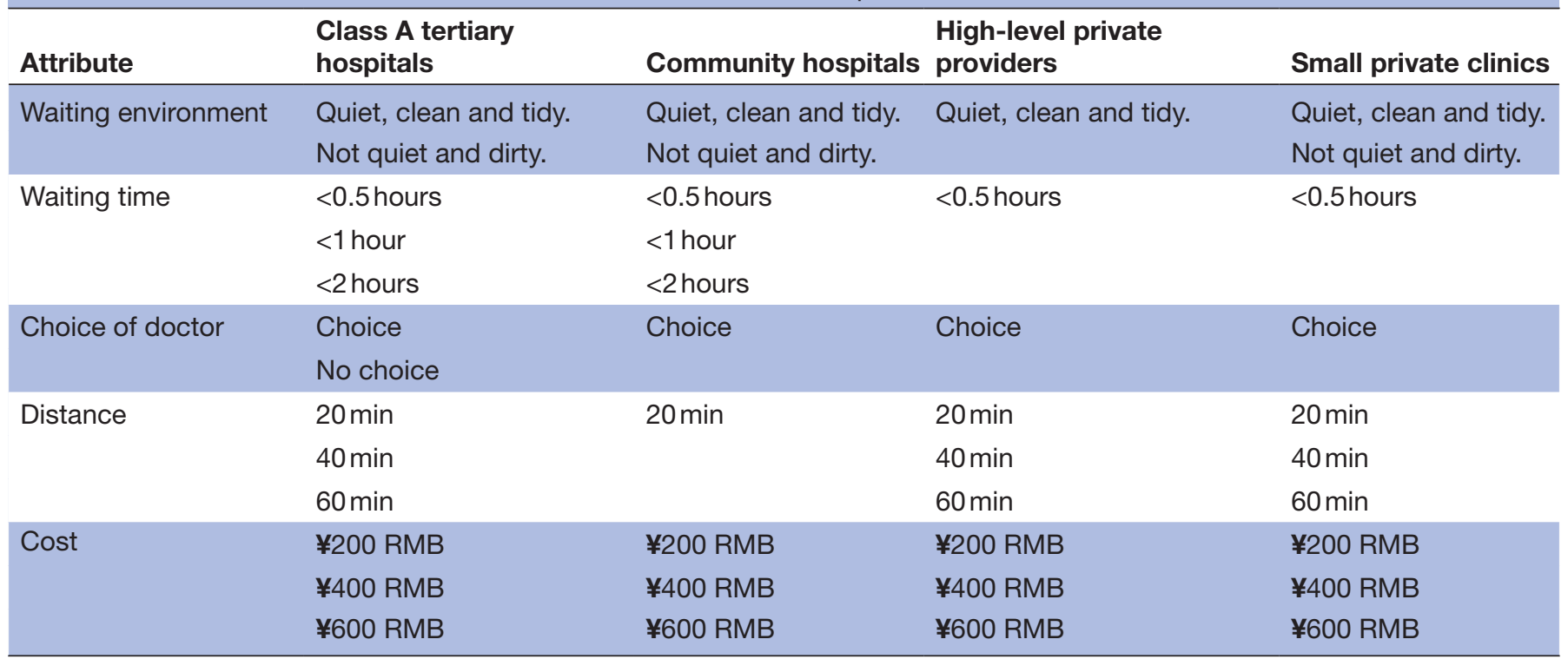

doctor and distance were allowed to differ across the four alternative dental care providers on offer. Prior evidence suggests that unforced options are preferable. ${ }^{33}$ However, given that the options in our DCE are a fair reflection of the healthcare reality in China, no opt-out option was offered to reduce the cognitive burden of respondents. ${ }^{34}$ The final design comprised 27 different sets of choices. To simplify the survey for respondents, we divided these sets into three blocks, each containing nine sets. Furthermore, we add a set, the same as the second set, at the end of each survey as an irrationality check of the questionnaire. Every respondent needed to answer the sociodemographic questions in part 1 , and the 10 choice sets followed in part 2 of one survey version. An example choice set is provided in table 2 .

\section{Data collection}

The data set was collected by a market research company that specialises in online surveys. Beijing residents over 18 years old who had previously been treated for a dental condition were qualified to take part. We chose Beijing because it is typical of a Chinese city with a fast-developing private healthcare market.
In each scenario, respondents were asked to imagine they were suffering from a toothache and must choose a facility from the following options (class A tertiary hospital, community hospital, high-level private hospital and small private clinic) for a filling. The guideline of the questionnaire includes a detailed description of the attributes and levels to help respondents making trade-off associated with their decisions.

A total of 684 questionnaires were collected, of which 576 were eligible for data analysis. While there is limited consensus on appropriate sample sizes for DCE studies, our sample satisfies the minimum size suggested by most researchers. ${ }^{35-37}$ Data collection was conducted between October and December of 2017.

\section{Analysis}

Data analysis in a DCE is based on random utility theory, ${ }^{38}$ where utility $U_{n j t}$ is decomposed into a systematic component $\left(V_{n j t}\right)$ and a random component $\left(\varepsilon_{n j t}\right) . U_{n j t}$ is the utility respondent $n$ derives from alternative $j$ on choice occasion $t$ :

$$
U_{n j t}=V_{n j t}+\varepsilon_{n j t}=X_{n j t} \beta+\varepsilon_{n j t}
$$

Table 2 Example of choice set

\section{When you have a cavity, which hospital would you choose?}

\begin{tabular}{|c|c|c|c|c|}
\hline Attribute & Class A tertiary hospital & Community hospital & High-level private hospital & Small private clinic \\
\hline Waiting environment & Quiet, clean and tidy. & Not quiet and dirty. & Quiet, clean and tidy. & Quiet, clean and tidy. \\
\hline Waiting time & 1 hour & 1 hour & 0.5 hours & 0.5 hours \\
\hline Distance & $60 \mathrm{~min}$ & $20 \mathrm{~min}$ & $40 \mathrm{~min}$ & $40 \mathrm{~min}$ \\
\hline Cost & $¥ 400 \mathrm{RMB}$ & $¥ 200 \mathrm{RMB}$ & $¥ 600 \mathrm{RMB}$ & $¥ 600$ RMB \\
\hline
\end{tabular}


where $X_{n i t}$ is an explanatory vector of the attribute and $\beta$ is the coefficient vector of the corresponding preference parameter. The selected alternative has a higher total utility than the other options in one set.

A range of models based on Eq. (1) can be developed to analyse discrete choices. ${ }^{8}$ Mixed logit model and latent class model have obvious advantages over standard multinomial estimation, as they contain more relaxed assumptions about preference homogeneity and the independence of irrelevant alternatives, which may lead to biased parameter estimates. ${ }^{3940}$ Mixed logit model assumes the distribution of $\varepsilon_{n j t}$ for random coefficients are specified, usually as normal distributions. Hence, both preference and scale heterogeneity can be modelled together. We used the mixed logit model in R software environment for Windows for our data analysis to confirm the panel structure of the data sets and to ensure potential heterogeneity in the preferences was taken into account. To calculate the marginal utility of price-that is, the marginal willingness to pay-we assigned the parameters $(\beta)$ with normal distributions to the attributes through 500 Halton draws, except for the cost. Latent class models explicitly model preference heterogeneity across individuals using a continuous distribution. ${ }^{41}$ Therefore, we also used the latent class model in Latent GOLD Choice 5.1 to account for clustering. The optimal number of classes was selected using a Bayesian information criterion.

Willingness to pay (WTP) represents the marginal utility participants are willing to pay for a particular change in attribute into dollar units. ${ }^{42}$ Each of the attribute levels (except for cost) was coded with an estimated independent coefficient. After testing for linearity, cost was coded with a continuous linear distribution. Then, the WTP was calculated algebraically on the basis of the estimated coefficients using a utility equation. For example, to calculate the WTP for reducing the waiting time from 1 hour to $30 \mathrm{~min}$, we used the following formula:

$$
\mathrm{WTP}=-\frac{\beta_{\text {lhours }}-\beta_{0.5 \text { hours }}}{\beta_{\text {cost }}}
$$

where $\beta_{\text {cost }}$ is the estimated coefficient of the cost attribute, and $\beta_{\text {1hours }}$ and $\beta_{0.5 \text { hours }}$ are the coefficients of the waiting time for 1 hour and $30 \mathrm{~min}$, respectively. This same approach was used to calculate the WTPs for all other features.

\section{Patient and public involvement}

We involved patients and the public throughout the study. The development of the research question and outcome measures was identified by the review panel who included patients. Patients had a key role in shaping the review questions, the methods, the interpretation of the data and the formation of key recommendations. Patients shaped the design of the review, contributing to the design of the methods for data collection. Patients particularly emphasised the importance of the type of private provider on their health care seeking decision. The study findings will be disseminated through multiple channels including publication, meetings, conferences and social media.

\section{RESULTS}

\section{Sample characteristics}

A summary of the demographic characteristics of the respondents is provided in table 3 . Of the 576 valid participants, $282(48.96 \%)$ were women, which is similar to the ratio in the Sixth National Population Census of China. The average age of the respondents was 35 years. Just over half the respondents had a university or higher degree, and 555 were covered by some type of medical insurance. Across the sample, 393 were Beijing native, and 183 were temporary migrants without Beijing Hukou. The majority of the participants had had prior experiences with public healthcare providers and nearly half had had experiences with private healthcare.

\section{DCE results}

The results of mixed logit analysis are provided in table 4 . In general, the coefficient with the greatest magnitude was hospital type. The estimated means for community hospitals $(\beta=-1.086, \mathrm{p}<0.001)$, high-level private hospitals $(\beta=-0.731, p<0.001)$ and private clinics $(\beta=-2.214$, $\mathrm{p}<0.001)$ labels were statistically significant, suggesting that, when controlled for attribute differences, people were on average less likely to choose a high-level private hospital for dental treatment. The results were even worse for community hospitals, and the most disliked provider was private clinics. Surprisingly, and against our expectations, the coefficient for the value of high-level private hospitals is greater than for community hospitals, which indicates that high-level private hospitals were more acceptable to the respondents. The remaining coefficients followed the expected trend, which indicates that all attributes were significant factors in the respondents' decisions. As expected, people in China prefer a healthcare facility that is: close by, has a clean and quiet and waiting room, offers the option to choose a doctor and has less waiting time and cost. Additionally, the estimated SD were large and significant, which signals considerable heterogeneity in the participants' preferences for specific attribute levels.

\section{Marginal willingness to pay}

The marginal rate of substitution represents the rate at which the participants were willing to trade-off gains relative to one criterion against losses relative to another. Table 5 shows the calculated values for WTP, which represents the relative importance of each of the attribute levels. The results indicate that, all else being equal, respondents valued the type of provider the most and were willing to pay RMB $¥ 479$ more to receive their care in a tertiary hospital rather than a small private clinic, RMB $¥ 215$ more over a community hospital and RMB $¥ 154$ more over high-level private hospital. Waiting time was revealed to be another important attribute of outpatient 


\begin{tabular}{|c|c|c|c|c|c|c|c|c|}
\hline & Block 1 & $\%$ & Block 2 & $\%$ & Block 3 & $\%$ & Total & $\%$ \\
\hline \multicolumn{9}{|l|}{ Gender } \\
\hline Male & 98 & 49.49 & 96 & 50.00 & 100 & 53.76 & 294 & 51.04 \\
\hline Female & 100 & 50.51 & 96 & 50.00 & 86 & 46.24 & 282 & 48.96 \\
\hline Age & 35.31 & & 36.02 & & 34.95 & & 35.43 & \\
\hline \multicolumn{9}{|l|}{ Education } \\
\hline High school or below & 41 & 20.71 & 56 & 29.17 & 30 & 16.13 & 127 & 22.05 \\
\hline Vocational diploma & 51 & 25.76 & 35 & 18.23 & 62 & 33.33 & 148 & 25.69 \\
\hline Undergraduate degree & 79 & 39.90 & 64 & 33.33 & 78 & 41.94 & 221 & 38.37 \\
\hline Postgraduate degree & 27 & 13.64 & 37 & 19.27 & 16 & 8.60 & 80 & 13.89 \\
\hline \multicolumn{9}{|l|}{ Monthly income } \\
\hline$<5000$ & 46 & 23.23 & 37 & 19.27 & 45 & 24.19 & 128 & 22.22 \\
\hline 5000-8000 & 48 & 24.24 & 67 & 34.90 & 48 & 25.81 & 163 & 28.30 \\
\hline $8000-15000$ & 50 & 25.25 & 50 & 26.04 & 79 & 42.47 & 179 & 31.08 \\
\hline$>15000$ & 54 & 27.27 & 38 & 19.79 & 14 & 7.53 & 106 & 18.40 \\
\hline \multicolumn{9}{|l|}{ Medical insurance } \\
\hline Employee medical insurance & 141 & 71.21 & 120 & 62.50 & 146 & 78.49 & 407 & 70.66 \\
\hline Residents medical insurance & 44 & 22.22 & 68 & 35.42 & 36 & 19.35 & 148 & 25.69 \\
\hline Commercial medical insurance & 33 & 16.67 & 15 & 7.81 & 8 & 4.30 & 56 & 9.72 \\
\hline Self-expense & 13 & 6.57 & 4 & 2.08 & 4 & 2.15 & 21 & 3.65 \\
\hline \multicolumn{9}{|l|}{ Hukou } \\
\hline Native & 129 & 65.15 & 136 & 70.83 & 128 & 68.82 & 393 & 68.21 \\
\hline Migrant & 69 & 34.85 & 56 & 29.17 & 58 & 31.18 & 183 & 31.77 \\
\hline \multicolumn{9}{|l|}{ Previous hospital experience } \\
\hline Public hospital experience only & 96 & 48.48 & 100 & 52.08 & 112 & 60.22 & 308 & 53.47 \\
\hline Clinic experience only & 28 & 14.14 & 29 & 15.10 & 15 & 8.06 & 72 & 12.50 \\
\hline Public hospital and clinic experience & 74 & 37.37 & 63 & 32.81 & 59 & 31.72 & 196 & 34.03 \\
\hline Total & 198 & & 192 & & 186 & & 576 & \\
\hline
\end{tabular}

care. Respondents were willing to pay RMB $¥ 177$ for a decrease in waiting time from 2 hours to 0.5 hours. On average, respondents were willing to pay RMB $¥ 125$ to enjoy a quiet, clean and tidy waiting room instead of a noisy and dirty one. The respondents also disliked travelling longer distances to a provider and reducing the travel time from 1 hour to 20 min was valued at RMB $¥ 147$. In addition, the option of being able to choose their doctor was valued at over RMB $¥ 117$.

\section{Heterogeneity analysis}

We used a latent class model to account for unobserved heterogeneity in the respondents' preferences by classifying respondents with a distinct preference for outpatient care. Dummy code alternative specific constants were given to the dependent variables in the model to represent the respondents' attitudes towards community, high-level private and small private hospitals compared with class A tertiary hospitals. To ensure that the dummy coded constants only reflected the preferences for provider type, the rest of the categorical attributes were effect coded. The resulting final model was a four-class model with a minimum bayesian information criterion (BIC) value of 3456.7. Table 6 presents the results of latent class model. The first column lists the attributes and levels; the last column lists $\mathrm{p}$ values for differences in parameter estimates across different classes; the other columns show the coefficient for each attribute level, with the estimated SEs in parentheses.

Age, income, prior experience and Hukou are identified as important factors in explaining preference heterogeneity. Members of class 1 preferred outpatient services with public providers over private providers. Respondents with Beijing Hukou and no private health provider experience had a higher probability of belonging to this class. Members of class 2 were somewhat less sensitive to the type of provider. Age and previous private health provider experience increased the probability of belonging to this group. The members of class 3 tended to be younger and have higher incomes. Members of this group revealed a strong preference for outpatient care in high-level private 
Table 4 DCE: estimated results of the mixed logit model with and without interactions for attribute levels

\begin{tabular}{|c|c|c|c|c|}
\hline \multirow{2}{*}{$\begin{array}{l}\text { Attribute } \\
\text { Level }\end{array}$} & \multirow[b]{2}{*}{ Coefficient } & \multirow[b]{2}{*}{ SE } & \multirow[b]{2}{*}{ SD } & \multirow[b]{2}{*}{ SE } \\
\hline & & & & \\
\hline \multicolumn{5}{|l|}{ Waiting environment } \\
\hline Not quiet and dirty & $-0.579^{* * *}$ & 0.0603 & $0.943^{\star \star *}$ & 0.026 \\
\hline \multicolumn{5}{|l|}{ Waiting time } \\
\hline No more than 1 hour & $-0.469^{\star * \star}$ & 0.0594 & $0.635^{\star \star \star}$ & 0.110 \\
\hline No more than 2 hours & $-0.818^{\star \star \star}$ & 0.0641 & $-1.258^{\star * *}$ & 0.108 \\
\hline \multicolumn{5}{|l|}{ Choice of doctor } \\
\hline \multicolumn{5}{|l|}{ Choice } \\
\hline No choice & $-0.545^{\star \star \star}$ & 0.0936 & $0.959^{\star \star \star}$ & 0.287 \\
\hline $40 \min$ & $-0.417^{\star * \star}$ & 0.0625 & 0.0881 & 0.130 \\
\hline $60 \min$ & $-0.680^{\star \star \star}$ & 0.0683 & $0.548^{\star \star \star}$ & 0.014 \\
\hline Cost & $-0.00462^{\star \star \star}$ & 0.000144 & & \\
\hline \multicolumn{5}{|l|}{ Hospital type } \\
\hline \multicolumn{5}{|l|}{ Class A tertiary hospital } \\
\hline Community hospital & $-0.997^{\star \star \star}$ & 0.0638 & $0.986^{\star \star \star}$ & 0.115 \\
\hline High-level private hospital & $-0.713^{\star * \star}$ & 0.0638 & $3.214^{\star \star \star}$ & 0.0867 \\
\hline Small private clinic & $-2.214^{\star \star \star}$ & 0.0826 & $3.627^{\star \star \star}$ & 0.0342 \\
\hline
\end{tabular}

${ }^{*} p<0.05,{ }^{* *} p<0.01,{ }^{\star * *} p<0.001$.

hospitals. They also had strong preferences for a quiet, clean and tidy waiting room, the less waiting time and the option to choose their doctor. Lastly, members of class 4 were more likely to choose small public hospitals and were more sensitive to cost. Older, migrants and people with below-average incomes were more likely to fall within this class. The average probabilities for class membership were: class 1: $51 \%$, class 2: $26 \%$, class 3: $18 \%$ and class 4 : $5 \%$.

\section{DISCUSSION}

In fact, the provider's type was the most important determinant in choosing a provider. Class A tertiary hospitals still dominate; however, when health providers were subdivided beyond just public or private, the overwhelming predominance of public label became somewhat questionable. Outpatients may prefer to be treated at a high-level private hospital rather than a public community hospital. This is also reflective of the chaos in China's current private healthcare market. Until recently, discrimination towards private healthcare providers could be largely attributed to widespread distrust in small low-level private providers. Public health sectors have a long and robust history in China and high-level private providers have just emerged in recent years. Surprisingly, and against our expectations, the preference for high-level hospitals is over some of the public health sectors (community hospitals). That is due largely to the insufficient of experienced physicians and therapeutic facilities in community hospitals. Another possible explanation is the substantial efforts that modern high-level private hospitals have made to improve the quality of their medical services. Also, the new alliance system, which allows for higher quality, more convenient and more personalised services, may have enhanced people's trust in private facilities. Furthermore, in January 2015, the state relaxed its policy restrictions on doctors practising in multiple locations. The policy of doctor practising in mutiple locations allows doctors, and especially specialists, to circulate between the public and private healthcare providers. On benifit of this policy, pivate hostipals could invite specialists from public hospitals to practise in their hospitals, which may be reducing some of the public doubts about the level of medical expertise in for-profit private hospitals. In spite of the encouraging results for private hospitals, a big concern needs to be solved on the development of community hospitals. Since numbers of empirical evidence have indicated the importance of establishing a greater primary care service, it is necessary for policy makers to make it imperative to reinstate the development of a strong and effective primary care system, providing more accessible, affordable and equitable basic 
Table 5 Marginal willingness to pay (WTP) for each attribute in model B

\begin{tabular}{|c|c|c|}
\hline Attribute and level & Coefficient & WTP (¥ RMB) \\
\hline \multicolumn{3}{|l|}{ Waiting environment } \\
\hline \multicolumn{3}{|l|}{ Quiet, clean and tidy } \\
\hline Not quiet and dirty & $-0.579^{\star \star \star}$ & 125.32 \\
\hline \multicolumn{3}{|l|}{ Waiting time } \\
\hline \multicolumn{3}{|l|}{ No more than 0.5 hours } \\
\hline No more than 1 hour & $-0.469^{\star \star \star}$ & 101.52 \\
\hline No more than 2 hours & $-0.818^{\star \star *}$ & 177.06 \\
\hline \multicolumn{3}{|l|}{ Choice of doctor } \\
\hline \multicolumn{3}{|l|}{ Choice } \\
\hline No choice & $-0.545^{\star \star \star}$ & 117.97 \\
\hline \multicolumn{3}{|l|}{ Distance } \\
\hline \multicolumn{3}{|l|}{$20 \min$} \\
\hline $40 \mathrm{~min}$ & $-0.417^{\star \star \star}$ & 90.26 \\
\hline $60 \mathrm{~min}$ & $-0.680^{\star \star \star}$ & 147.19 \\
\hline Cost & $-0.00462^{\star \star \star}$ & \\
\hline \multicolumn{3}{|l|}{ Hospital type } \\
\hline \multicolumn{3}{|l|}{ Class A tertiary hospital } \\
\hline Community hospital & $-0.997^{\star \star \star}$ & 215.80 \\
\hline High-level private hospital & $-0.713^{\star \star \star}$ & 154.32 \\
\hline Small private clinic & $-2.214^{\star \star \star}$ & 479.22 \\
\hline
\end{tabular}

${ }^{*} \mathrm{P}<0.05,{ }^{* \star} \mathrm{p}<0.01,{ }^{* \star *} \mathrm{p}<0.001$.

healthcare. Some applicable interagency responses, such as the medical treatment alliance combining hospital and primary healthcare networks, may be useful to improve the quality of community care.

Turning to the other attributes, in reality, the ability to choose a particular doctor is specific to class A tertiary hospitals. The estimated coefficient of not having the option to choose a doctor was statistically significant, which indicates that imposing restrictions on the choice of physician may deter some patients from public hospitals. Additionally, prior studies also show that an inability to choose one's physician reduces patient satisfaction, ${ }^{44} 45$ which raises questions for managers in terms of their own trade-offs between optimising resource allocations and patient satisfaction.

We further examined the heterogeneity of patient preferences for each attribute and each attribute level. The greatest heterogeneity was detected by the alternative specific constants. Younger people and people with higher incomes tended to be more sensitive to long waiting times and poor waiting environment. Older people and people with lower incomes cared more about travel times and cost. Non-Beijing Hukou holders showed less discrimination towards non-tertiary public hospitals, especially private providers. The respondents' previous experiences may also explain preference heterogeneity, in that private providers were more attractive to those with previous experiences of private healthcare. These results were according with previous study: younger, high-to-medium income group or urban residents paid more attention to factors such as waiting time, services attitude and showed more doubts about the level of primary and clinics care. While those people in elder age, people with low to middle income or migrates from rural to urban appreciated more about the rational charge and convenience of medical treatment (more sensitivity to the distance in our study). ${ }^{46}$ The findings suggest that the more vulnerable people (eg, socioeconomically disadvantaged) are more willing to access general practitioner (GP) care, which indicate less discriminate against low-equipped healthcare sectors, and presumably are easier to be affected by financial attribute (cost). Thus, those older, lower income group and migrant should be given more attention and support to promote the equity in healthcare. This has important implications for policy makers already seeking to 'close the gap' and reduce health inequalities.

In terms of classifications, younger people with higher incomes were more likely to be willing to be treated at a high-level private hospital (class 3). The estimated coefficients for this class show these people pay more attention to experience across the entire healthcare service process which, again, provides valuable guidance for private hospitals to target their customers. Healthcare managers should provide more support with high-level private hospitals on their further development, at the same time exercising rigorous medical quality supervision to make private hospitals more acceptable for the public, so as to reduce the burden of class A tertiary hospitals. In addition, if private hospitals can truly cooperate with public hospitals, the results of this study will provide meaningful insights into the most appropriate roles they can play within medical alliances. Non-Beijing Hukou holders with low income showed significantly less discrimination towards small private clinics (class 4 ). This finding is consistent with previous studies that, in China, rural-to-urban migrants lacking local Hukou status in their residential areas have lower access to public hospital healthcare. Hence, they show less discrimination towards private hospitals. ${ }^{47} 48$ However, reforms to these treatment policies are already on the agenda, which should relieve the difficulties migrants have in accessing public healthcare. In future, the development of small private clinics may become an important question that needs to be discussed. Furthermore, the different patterns of preferences observed for different groups of participants, in different conditions, suggests government and other decision makers should focus their efforts on key cohorts if seeking to raise support for their health reforms.

It is worth noting that more than half the respondents still expressed strong preference for public healthcare providers, especially class A tertiary hospitals (class 1 ). Previous studies find that patients often attach greater importance to their own healthcare experience than to comparative information. ${ }^{49}$ Most patients do not look for the highest quality care for the minimum cost. Rather, 
Table 6 Estimated results of the latent class model

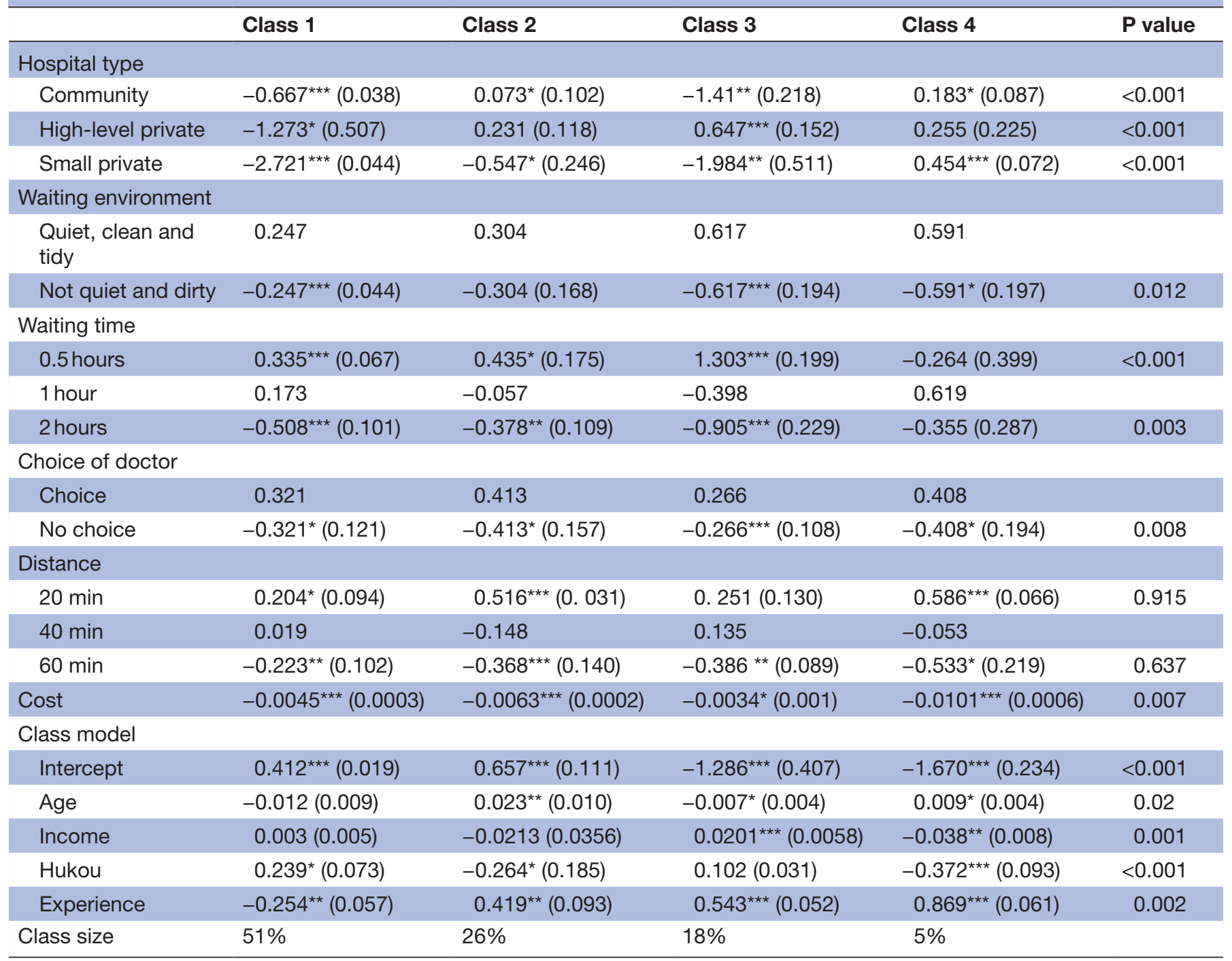

${ }^{*} \mathrm{P}<0.05,{ }^{* *} \mathrm{p}<0.01,{ }^{* * *} \mathrm{p}<0.001$.

they often opt to stay with their current provider, as positive experience influences their attitudes and future choices. ${ }^{49}{ }^{50}$ Moreover, familiarity may also play a role, as people tend to develop a preference merely because they are familiar with it. ${ }^{50}$ Chinese people are typically more familiar with public hospital services and have also shown deep trust in them due to long-term historical customs. Thus, it is reasonable that such a large proportion of respondents expressed an overwhelming preference for public hospitals. Furthermore, familiarity could also explain why migrants are more acceptable to being treated by small private clinics, given studies on healthcare in China have already found that rural-to-urban migrants commonly used the private sector (usually low-level clinics) before moving and continue to do so after. ${ }^{47}$ Based on these results, using restrictive measures, such as the recent policy that claimed will compulsively remove the outpatient departments in tertiary hospitals, to restrict the Chinese patients may give rise to a sharp drop in satisfaction by the fact that they have to see doctors with dubious qualifications in community health centres after enjoying many years of freedom. The general public's traditional perceptions may rather be more difficult to change than health policy makers might think. It will take time for Chinese people's mindset and behaviour to change. Further efforts towards radically changing people's perceptions and behaviour towards the public-private dimension of healthcare might involve appropriate policy incentives and effective propaganda and education schemes about various aspects of the outpatient care delivered by private providers.

In closing, this study has a number of limitations. Some meaningful attributes may have been excluded from the experiment design due to survey constraints. In addition, the use of labels in the DCE may have augmented the importance of provider types if the participants focused too much on the labels than the other attributes. A substantial percentage of participants (approximately $18 \%$ ) had a dominant and specific preference for class A tertiary hospitals-a labelled attribute in the DCE. 
Although, this finding is similar to the results derived in the Bekker-Grob study, which compared labelled and unlabelled DCEs. ${ }^{51}$ To elicit preferences with more confidence in future, further confirmation from data on actual choices is needed.

\section{CONCLUSIONS}

The choice of healthcare providers is more than an academic question in China. In an attempt to provide a better understanding of the healthcare-seeking behaviour of China's general public, our research moved beyond previous works by studying a much more specific set of demands and preferences for outpatient care. On average, class A tertiary hospitals still reflect the most preferred choice for the general public, but highlevel private hospitals are more popular than community hospitals for outpatient services. However, patients often make different choices in comparable situations. Hence, ignoring heterogenic preferences may undermine the validity of research findings. The preference heterogeneity we found was relatively large and can partly be explained by age, income, Hukou status and the respondents' previous experiences of healthcare. This is an important consideration from a policy perspective if one's aim is greater personalisation of healthcare. Thus, our work provides substantial policy implications in China's current context of medical reform. Policy makers should take serious account of a policy's pros and cons before implementation, especially those related to patient preferences. Moreover, it would also be helpful for private healthcare providers to seek out appropriate development strategies to promote cooperation and/or competition with public hospitals.

\section{Acknowledgements The authors would like to thank all the interviewers and participants who support the current study.}

Contributors JL and JZ conceived and designed the experiments; JZ, ZZ, HL and LC performed the experiments; JZ and ZZ analysed the data; JZ and HL contributed reagents/materials/analysis tools; JZ and JL wrote the paper.

Funding This work was supported by the National Natural Science Foundation of China (grant no. 71432002) and the International Graduate Exchange Program of Beijing Institute of Technology.

Competing interests None declared.

Patient consent for publication Not required.

Provenance and peer review Not commissioned; externally peer reviewed.

Data sharing statement Data will be available on request to corresponding author.

Open access This is an open access article distributed in accordance with the Creative Commons Attribution Non Commercial (CC BY-NC 4.0) license, which permits others to distribute, remix, adapt, build upon this work non-commercially, and license their derivative works on different terms, provided the original work is properly cited, appropriate credit is given, any changes made indicated, and the use is non-commercial. See: http://creativecommons.org/licenses/by-nc/4.0/.

\section{REFERENCES}

1. Xue X. Annual Report on China's Private Hospitals Development (2017). Beijing, China: Social Sciences Academic Press, 2018.
2. Ministry of Health. The number of health institutions in China by the end of November. 2017 http://www.moh.gov.cn/mohwsbwstjxxzx/ s7967/201803/f2b3c97fb3d84ac1a31e61211d032c60.shtml (Accessed 16 Mar 2018).

3. Ministry of Health. National medical service in November. 2017 http://www.moh.gov.cn/mohwsbwstjxxzx/s7967/201803/9a962a80 61c84afbb430d36751dc7344.shtml (Accessed 16 Mar 2018).

4. Tang C, Zhang Y, Chen L, et al. The growth of private hospitals and their health workforce in China: a comparison with public hospitals. Health Policy Plan 2014;29:30-41.

5. Barbieri E, Huang M, Pi S, et al. Restructuring the production of medicines: an investigation on the pharmaceutical sector in china and the role of mergers and acquisitions. Int $J$ Environ Res Public Health 2017:14:1179.

6. Li L, Fu H. China's health care system reform: Progress and prospects. Int J Health Plann Manage 2017;32:240-53.

7. Epstein RM, Fiscella K, Lesser CS, et al. Why the nation needs a policy push on patient-centered health care. Health Aff 2010;29:1489-95.

8. Hauber AB, González JM, Groothuis-Oudshoorn CG, et al. Statistical methods for the analysis of discrete choice experiments: a report of the ISPOR Conjoint Analysis Good Research Practices Task Force. Value Health 2016;19:300-15.

9. Veldwijk J, Determann D, Lambooij MS, et al. Exploring how individuals complete the choice tasks in a discrete choice experiment: an interview study. BMC Med Res Methodol 2016;16:45.

10. Brown P, Panattoni L, Cameron L, et al. Hospital sector choice and support for public hospital care in New Zealand: Results from a labeled discrete choice survey. J Health Econ 2015;43:118-27.

11. Tang $\mathrm{C}, \mathrm{Xu} \mathrm{J}$, Zhang $\mathrm{M}$. The choice and preference for publicprivate health care among urban residents in China: evidence from a discrete choice experiment. BMC Health Serv Res 2016;16:11.

12. Kiiskinen U, Suominen-Taipale AL, Cairns J. Think twice before you book? Modelling the choice of public vs private dentist in a choice experiment. Health Econ 2010;19:670-82.

13. McCollum R, Chen L, ChenXiang $\mathrm{T}$, et al. Experiences with primary healthcare in Fuzhou, urban China, in the context of health sector reform: a mixed methods study. Int J Health Plann Manage 2014;29:e107-e126.

14. Sarma S. Demand for outpatient healthcare. Appl Health Econ Health Policy 2009;7:265-77.

15. Hole AR. Modelling heterogeneity in patients' preferences for the attributes of a general practitioner appointment. $J$ Health Econ 2008;27:1078-94.

16. Goossens LM, Utens CM, Smeenk FW, et al. Should I stay or should I go home? A latent class analysis of a discrete choice experiment on hospital-at-home. Value Health 2014;17:588-96.

17. Chan KW, Liu T, Yang Y. Hukou and non-hukou migrations in China: comparisons and contrasts. Int J Popul Geogr 1999;5:425-48.

18. Guo J, Guan L, Fang L, et al. Depression among Chinese older adults: a perspective from Hukou and health inequities. $J$ Affect Disord 2017;223:115-20.

19. Koeneman MM, Essers BA, Gerestein CG, et al. Treatment of cervical intraepithelial neoplasia: patients preferences for surgery or immunotherapy with imiquimod. J Immunother 2017;40:148-53.

20. Sagebiel J. Preference heterogeneity in energy discrete choice experiments: a review on methods for model selection. Renewable and Sustainable Energy Reviews 2017;69:804-11.

21. Scuffham PA, Ratcliffe J, Kendall E, et al. Engaging the public in healthcare decision-making: quantifying preferences for healthcare through citizens' juries. BMJ Open 2014;4:e005437.

22. Ryan M. Discrete choice experiments in health care. BMJ 2004;328:360-1.

23. Danyliv A, Pavlova M, Gryga I, et al. Preferences for physician services in Ukraine: a discrete choice experiment. Int $J$ Health Plann Manage 2015;30:346-65.

24. Larson E, Vail D, Mbaruku GM, et al. Moving toward patientcentered care in africa: a discrete choice experiment of preferences for delivery care among 3,003 Tanzanian women. PLoS One 2015;10:e0135621

25. Coast J, Al-Janabi $\mathrm{H}$, Sutton EJ, et al. Using qualitative methods for attribute development for discrete choice experiments: issues and recommendations. Health Econ 2012;21:730-41.

26. Li L, Zhang LL, Zhu YG, et al. Influence factor analysis and countermeasure study of the potential medical demand of Chinese residents. Chin Health Econ 2006;25:36-9.

27. Yang $X, X u L$, Sun Y. Research on the influencing factors which affected the residents' choice of care provider in Dongying City. Chin Health Econ 2005;8:16. 
28. Dong-fu Q, Ai-tian Y, Qing-yue M. The analysis of the affecting factors on choice of health care providers by rural inpatients in Gansu Province. Chin Health Econ 2008;1:20.

29. Qian D, Lucas H, Chen J, et al. Determinants of the use of different types of health care provider in urban China: a tracer illness study of URTI. Health Policy 2010;98:227-35.

30. Street DJ, Burgess L. The construction of optimal stated choice experiments: theory and methods. Sydney, Australia: John Wiley \& Sons, 2007.

31. Huber J, Zwerina K. The importance of utility balance in efficient choice designs. Journal of Marketing Research 1996;33:307-17.

32. Scarpa R, Rose JM. Design efficiency for non-market valuation with choice modelling: how to measure it, what to report and why ${ }^{\star}$. Aust $J$ Agric Resour Econ 2008;52:253-82.

33. Dhar R, Simonson I. The effect of forced choice on choice. Journal of Marketing Research 2003;40:146-60.

34. Ryan M, Gerard K, Amaya-Amaya M. Using discrete choice experiments to value health and health care. Springer Netherlands: Dordrecht, 2008.

35. de Bekker-Grob EW, Donkers B, Jonker MF, et al. Sample size requirements for discrete-choice experiments in healthcare: a practical guide. Patient 2015;8:373-84.

36. Orme BK. Getting started with conjoint analysis: strategies for product design and pricing research. 2nd edn. Madison: Research Publishers LLC, 2010.

37. Lancsar E, Louviere J. Conducting discrete choice experiments to inform healthcare decision making: a user's guide. Pharmacoeconomics 2008;26:661-77.

38. Manski CF. The structure of random utility models. Theory Decis 1977;8:229-54.

39. Regier DA, Ryan M, Phimister E, et al. Bayesian and classical estimation of mixed logit: an application to genetic testing. J Health Econ 2009;28:598-610.

40. Lancsar E, Louviere J, Flynn T. Several methods to investigate relative attribute impact in stated preference experiments. Soc Sci Med 2007;64:1738-53.
41. Boxall PC, Adamowicz WL. Understanding heterogeneous preferences in random utility models: a latent class approach. Environmental and Resource Economics 2002;23:421-46.

42. De Valck J, Vlaeminck P, Broekx S, et al. Benefits of clearing forest plantations to restore nature? Evidence from a discrete choice experiment in Flanders, Belgium. Landsc Urban Plan 2014;125:65-75.

43. Gong CL, Hay JW, Meeker D, et al. Prescriber preferences for behavioural economics interventions to improve treatment of acute respiratory infections: a discrete choice experiment. BMJ Open 2016;6:e012739.

44. Laveist TA, Nuru-Jeter A. Is doctor-patient race concordance associated with greater satisfaction with care? J Health Soc Behav 2002;43:296-306.

45. Schmittdiel J, Selby JV, Grumbach K, et al. Choice of a personal physician and patient satisfaction in a health maintenance organization. JAMA 1997;278:1596-9.

46. Luo L, Luo L, He X, et al. Effects of distance on health seeking behaviors of outpatients in China's large hospitals: case of West China hospital of Sichuan university. Int J Clin Exp Med 2016;9:11923-33.

47. Mou J, Cheng J, Zhang D, et al. Health care utilisation amongst Shenzhen migrant workers: does being insured make a difference? BMC Health Serv Res 2009;9:214.

48. Goodburn C. Rural-urban migration and gender disparities in child healthcare in China and India. Dev Change 2014;45:631-55.

49. Victoor A, Delnoij DM, Friele RD, et al. Determinants of patient choice of healthcare providers: a scoping review. BMC Health Serv Res 2012;12:272.

50. Hol L, de Bekker-Grob EW, van Dam L, et al. Preferences for colorectal cancer screening strategies: a discrete choice experiment. Br J Cancer 2010;102:972-80.

51. de Bekker-Grob EW, Hol L, Donkers B, et al. Labeled versus unlabeled discrete choice experiments in health economics: an application to colorectal cancer screening. Value Health 2010;13:315-23. 